\title{
Tc-MYBPA is an Arabidopsis TT2-like transcription factor and functions in the regulation of proanthocyanidin synthesis in Theobroma cacao
}

\author{
Yi Liu ${ }^{1,4}$, Zi Shi', Siela N. Maximova², Mark J. Payne ${ }^{3}$ and Mark J. Guiltinan ${ }^{1,2^{*}}$
}

\begin{abstract}
Background: The flavan-3-ols catechin and epicatechin, and their polymerized oligomers, the proanthocyanidins (PAs, also called condensed tannins), accumulate to levels of up to $15 \%$ of the total weight of dry seeds of Theobroma cacao L. These compounds have been associated with several health benefits in humans. They also play important roles in pest and disease defense throughout the plant. In Arabidopsis, the R2R3 type MYB transcription factor TT2 regulates the major genes leading to the synthesis of PA.

Results: To explore the transcriptional regulation of the PA synthesis pathway in cacao, we isolated and characterized an R2R3 type MYB transcription factor MYBPA from cacao. We examined the spatial and temporal gene expression patterns of the TC-MYBPA gene and found it to be developmentally expressed in a manner consistent with its involvement in PAs and anthocyanin synthesis. Functional complementation of an Arabidopsis tt2 mutant with Tc-MYBPA suggested that it can functionally substitute the Arabidopsis TT2 gene. Interestingly, in addition to PA accumulation in seeds of the Tc-MYBPA expressing plants, we also observed an obvious increase of anthocyanidin accumulation in hypocotyls. We observed that overexpression of the TC-MYBPA gene resulted in increased expression of several key genes encoding the major structural enzymes of the PA and anthocyanidin pathway, including DFR (dihydroflavanol reductase), LDOX (leucoanthocyanidin dioxygenase) and BAN (ANR, anthocyanidin reductase).
\end{abstract}

Conclusion: We conclude that the TC-MYBPA gene that encodes an R2R3 type MYB transcription factor is an Arabidopsis TT2 like transcription factor, and may be involved in the regulation of both anthocyanin and PA synthesis in cacao. This research may provide molecular tools for breeding of cacao varieties with improved disease resistance and enhanced flavonoid profiles for nutritional and pharmaceutical applications.

Keywords: Theobroma cacao, Proanthocyanidin, Transcription factor, TT2

\section{Background}

Proanthocyanidins (PAs) are a subgroup of a large class of plant secondary metabolites known as flavonoids. Due to their important roles in plant defense and their beneficial role in human health, our understanding of PAs as well as the general flavonoid biosynthetic pathway has greatly improved in the past decades [1-5]. A general PA

\footnotetext{
* Correspondence: mjg9@psu.edu

${ }^{1}$ Huck Institute of Life Sciences, The Pennsylvania State University, University Park, PA 16802, USA

${ }^{2}$ Department of Horticulture, The Pennsylvania State University, 422 Life Sciences Building, University Park, PA 16802, USA

Full list of author information is available at the end of the article
}

synthesis pathway is summarized in Fig. 1. The mechanisms regulating the transcription of the flavonoid biosynthetic pathway genes are well studied in the model systems Arabidopsis (Arabidopsis thaliana) and maize (Zea mays) [6]. Transcriptional regulation of the genes encoding the key enzymes of the flavonoid pathway is mediated by members of three protein families: the R2R3-MYB transcription factors, the MYC-like basic helix-loop-helix (bHLH) proteins and the WD40 repeat proteins [6-8].

The regulation of proanthocyanidin (PA) synthesis has been well characterized by the analysis of transparent testa $(t t)$ mutants that fail to accumulate PAs in the seed

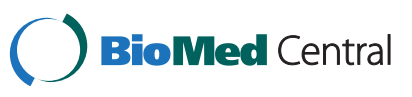

(C) 2015 Liu et al. This is an Open Access article distributed under the terms of the Creative Commons Attribution License (http://creativecommons.org/licenses/by/4.0), which permits unrestricted use, distribution, and reproduction in any medium, provided the original work is properly credited. The Creative Commons Public Domain Dedication waiver (http:// creativecommons.org/publicdomain/zero/1.0/) applies to the data made available in this article, unless otherwise stated. 


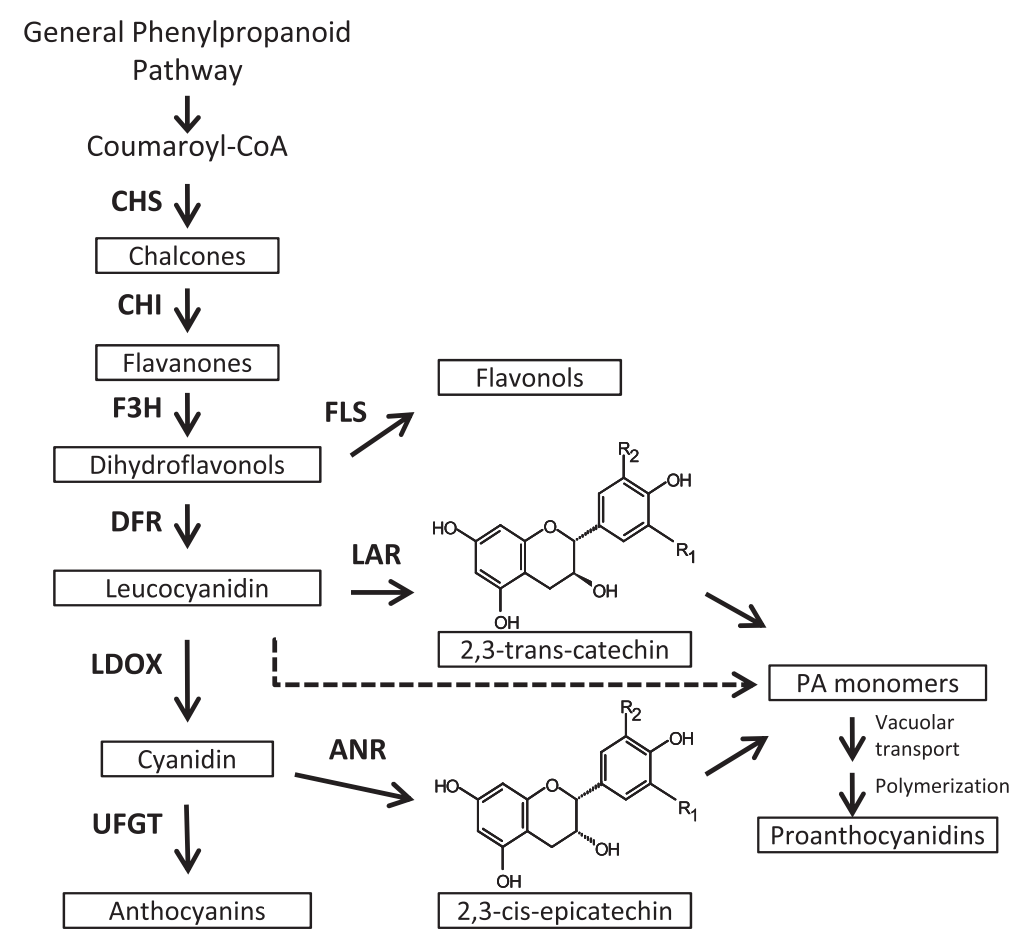

Fig. 1 Working model of Anthocyanin and Proanthocyanidin synthesis pathway adapted from [23]. Enzymes are represented in uppercase bold letters; the products in the pathway are given in black boxes. The enzymes involved in the pathway are shown as follows: $\mathrm{CHS}$, chalcone synthase; $\mathrm{CHI}$ chalcone isomerase; F3H, flavanone-3ß-hydroxylase; DFR, dihydroflavonol-4-reductase; LDOX, leucoanthocyanidin dioxygenase; FLS, flavonol synthase; LAR, leucoanthocyanidin reductase; ANR, anthocyanidin reductase; and UFGT, UDP-Glc.flavonoid-3-O-glucosyltransferase

coat $[6,9]$. Three TT loci, TT2, TT8 and TTG1, which encode R2R3-MYB, bHLH and WD40 repeat proteins respectively, are necessary for proper temporal and spatial accumulation of PAs [6]. The combinatorial interactions of different members from these three protein families determine the specificity of target gene activation $[4,6,10,11]$. This interaction has been shown for several flavonoids synthesis regulators isolated from Arabidopsis [4, 6, 10, 11], Zea mays [12,13] and Petunia hybrida [14-16]. The three proteins interact and form a ternary transcriptional protein complex to activate "late" PA-specific genes including DFR (dihydroflavanol reductase), LDOX (leucoanthocyanidin dioxygenase, also called ANS, anthocyanin synthase) and $B A N$ (ANR, anthocyanidin reductase) $[10,11,17,18]$. Another three TT loci, TT16, TT1 and TTG2 that encode a MADS box protein, a zinc-finger protein and a WRKY transcription factor, respectively, are also important for PA synthesis [6]. These proteins have been shown to regulate the expression of BAN protein through a posttranscriptional mechanism and thus are involved in the differentiation of PA-accumulating cells [6].

The TT2 gene product (TT2) is a key regulator of PA synthesis and confers target gene specificity to the MYBbHLH-WD40 complex. It is specifically expressed in PAaccumulating cells in Arabidopsis but can induce ectopic expression of the $B A N$ gene when constitutively expressed in the presence of a functional TT8 protein [10]. TT2 belongs to the large R2R3-MYB protein family that has 133 members in Arabidopsis. These proteins are typically involved in many aspects of plant secondary metabolism, plant cell identity and cell fate determination $[19,20]$. Members of the R2R3-MYB protein family are characterized by the presence of two highly conserved head-to-tail MYB motifs in the N-terminal region, the R2 and R3 repeats, although their $\mathrm{C}$-terminal regions are very divergent. Each of the R2R3 repeats consists of three $\alpha$-helices [12]; helix 3 of each motif is involved in interaction with DNA and helix 1 of the R3 repeat is important for corresponding bHLH recognition.

In addition to Arabidopsis, the TT2-like PA-specific R2R3-MYB transcription factors (TFs) have been characterized in grape (Vitis vinifera), Lotus (Lotus japonicus), poplar (Populus tremuloides), persimmon (Diospyros kaki), clover (Trifolium arvense) and Medicago (Medicago truncatula) [21-27]. In grape, two TT2-like MYB TFs (VvMYBPA1 and VvMYBPA2) have been identified [23, 24]. These TFs exhibit tissue-specific functions in inducing PA structural gene expression and synthesis: VvMYBPA1 is mainly expressed in seeds; and VvMYBPA2 is mainly in expressed in exocarp of 
young berries and in the leaves. Similar observations were reported in Lotus, in which three copies of TT2like R2R3-MYB TFs were identified that differed in organ-specific expression and responsiveness to stress [21]. Each of the TFs mentioned above is capable of activating the $A N R$ promoter in transient reporter assays. In poplar, a MYB134 gene encoding a TT2-like TF was recently shown to be responsive to wounding, pathogen presence and UV-B irradiation, consistent with the biological roles of PAs in anti-herbivore, antipathogen and UV damage protection [22]. Overexpression of MYB134 in poplar resulted in transcriptional activation of the genes encoding enzymes of the full PA biosynthesis pathway from PAL1 to ANR and LAR, but not FLS, which is specific to flavonol synthesis.

There are a variety of plant-based foods and beverages that serve as natural sources of flavonoids, including cacao, red wine, grape, apple and cranberries. Among those, cacao has an extraordinarily high amount of flavonoid, especially PAs [28], which make up about $10-14 \%$ of dry weight in mature beans [29]. The development of cacao and flavonoid (mainly anthocyanins) synthesis has been described previously [30]. The development of cacao fruits can be divided into three phases [31]. Following pollination and fertilization, the first phase of fruit development is initiated and fruit begins to expand slowly at a rate of about $30-40 \mathrm{~cm}^{3} /$ week [32]. This phase lasts $6-7$ weeks until the first division of the fertilized egg, which initiates the second phase of pod development. At the second phase, fruits expand more rapidly at a rate of about 110-130 $\mathrm{cm}^{3} /$ week, and embryos enlarge but remain unpigmented till they reach the length of ovules at about 14-16 weeks after pollination [31,33]. When the fruits are 14-16 weeks old, the pericarp begins to change color from green to orange (in Scavina 6), denoting onset of the third phase, ripening. Ripe pod color varies from bright red, purple, green, yellow and multi-colored patterns, dependent on genotype. During the third phase, the increase in the fruit external dimensions gradually slows and finally ceases. The seeds begin to solidify and their dry weight increases rapidly at a rate of about $20-40 \mathrm{mg} /$ day. Seed length remains constant as they continue to accumulate anthocyanins and gradually darken until maturity at about 20 weeks after pollination [30-33].

This research describes the isolation and characterization of a cacao gene, Tc-MYBPA, which encodes an R2R3MYB transcription factor involved in regulating the biosynthesis of cacao PAs. Constitutive expression of $T c-M Y B P A$ in the Arabidopsis tt2 mutant not only successfully complemented its primary phenotype (a PA-deficient seed coat) but also resulted in increased anthocyanin accumulation in young seedlings, suggesting that Tc-MYBPA may regulate both the anthocyanin and PA pathways in cacao.

\section{Results}

\section{The Cacao TC-MYBPA gene encodes an R2R3-MYB transcription factor}

Four putative $T c-M Y B P A$ cDNA sequences were identified in a collection of Theobroma cacao expressed sequence tags (ESTs) [34] by querying the cacao ESTtik database (http://esttik.cirad.fr/) with the protein sequence of Arabidopsis TT2 (accession no. Q9FJA2). This cacao EST database contains 56 cDNA libraries constructed from different organs; two main genotypes and different stress conditions thus could be considered as an exhaustive collection of cacao expressed genes [34]. ESTs showing sequence similarity to the TT2 gene were assembled into a contig to recover full-length open reading frames (ORFs) by alignment with cDNAs of homologous genes from other species and predictions from the ORF Finder program (www.ncbi.nlm.nih.gov/projects/ gorf/). The full-length coding sequence of $T c-M Y B P A$ was amplified by RT-PCR using cDNAs isolated from young leaves of cacao (Scavina 6), in which PAs are actively synthesized and accumulated [35]. The isolated ORF was named Tc-MYBPA (accession no. GU324346). By searching the newly assembled cacao genome [36], we identified the Tc-MYBPA gene (Tc01_g034240) that is 1477 -bp long with two exons. It is not associated with any currently identified quantitative trait loci (QTL) related to flavonoids. However, the Tc-MYBPA is very closely associated with 7 out of 17 DFR orthologous genes located near the bottom of chromosome 1 . We also searched the whole cacao genome with the protein sequence of Arabidopsis TT2 to check if there are other possible homologues genes. The search revealed 7 candidate genes with higher score than Tc-MYBPA (Additional file 1: Figure S1). However, we didn't find any confident hits by searching their putative protein sequences back to the cacao EST database. Considering that this EST database contains a variety of tissues that have been shown to synthesize and accumulate PAs [34, 37], including leaves, roots, flowers, pods, seeds, and seed testa, the 7 candidate genes maybe be peudogenes and not express at all.

The 864-bp ORF of Tc-MYBPA encodes a protein of 287 amino acids that shares $68 \%$ identity with grape VvMYBPA1. A protein sequence alignment of Tc$M Y B P A$ with other PA- and anthocyanin-regulating MYB proteins revealed that Tc-MYBPA contains an Nterminal R2R3 repeat that corresponds to the DNAbinding domain of plant MYB-type proteins (Fig. 1a). Like the high sequence similarity observed between the R2R3 repeat regions shared by 126 members of Arabidopsis [19, 38], the Tc-MYBPA R2R3 repeat region is highly conserved when compared to other plant R2R3 MYBs. The Tc-MYBPA N-terminal region also contains the $[\mathrm{D} / \mathrm{E}] \mathrm{LX}_{2}[\mathrm{R} / \mathrm{K}] \mathrm{X}_{3} \mathrm{LX}_{6} \mathrm{LX} \mathrm{X}_{3} \mathrm{R}$ motif for interaction with 
bHLH partners in the R3 repeat region [12], whereas the C-terminal region shows little homology to the MYB proteins included in this comparison.

To investigate these relationships more closely, a phylogenetic tree was constructed using the full-length amino acid sequences of Tc-MYBPA and sequences of all functionally tested MYBs involved in regulating proanthocyanidin and anthocyanin biosynthesis, as well as MYBs associated with several other biological processes (Fig. 1b). By searching the cacao EST database using tBLASTn with the protein sequence of putative cacao MYB Tc-MYBPA as the query, three EST contigs (CL8212Contig1, CL2621Contig1 and CL158Contig1) containing MYB-like proteins were also identified as the next best cacao matches to Tc-MYBPA. The results show that the putative cacao proanthocyanidin regulatory protein Tc-MYBPA is most closely related to the grape PA regulatory MYB protein VvMYBPA1 and clusters in the same clade with all the anthocyanidin and proanthocyanidin regulatory MYB proteins.

This clade also includes VvMYB5a and VvMYB5b from grape, which are involved in regulating the entire flavonoid pathway, and $\mathrm{PhPH} 4$ from petunia, which is involved in regulating vacuolar $\mathrm{pH}$. R2R3-type MYB proteins that regulate other biochemical and physiological processes such as phlobaphene and flavonol synthesis, cell shape determination and trichome development clustered into separate subgroups. The other three cacao MYB-like proteins cluster together with MYBs that have functions other than proanthocyanidin regulation, such as flavonoid pathway regulation (CL8212Contig1), cell shape determination (CL2621Contig1) and anthocyanidin synthesis regulation (CL158Contig1). ZmC1, the maize anthocyanin synthesis regulator that was shown to activate the Arabidopsis ANR promoter [11], clustered together in the same subgroup with AtTT2 and VvMYPPA2, which are functionally verified PA regulators. This was consistent with the protein alignment analysis in which $\mathrm{ZmC1}$ was more similar to PA regulatory MYBs than to anthocyanin regulatory MYBs. Protein alignment also revealed that some conserved amino acids present in the N-terminal region of Tc-MYBPA as well as all PA regulatory MYB proteins and $\mathrm{ZmC1}$ were absent in all the other anthocyanin MYB factors (Fig. 2); this could indicate similarity in function. These included, according to position on Tc-MYBPA, His32, Gly50, Ile70, Asp101, Glu103, and Ile104.

In summary, the $T c-M Y B P A$ protein sequence includes conserved R2R3 regions typical of plant MYB transcription factors. Moreover, in Tc-MYBPA, we were able to detect conserved amino acid homologies shared with all the TT2-like MYB regulators but absent in anthocyanin regulators. These conserved amino acids appear to be specific to this clade and may be used to identify candidate PAspecific MYB regulators from other plant species.

\section{Expression of Tc-MYBPA correlates with PA accumulation in Theobroma cacao}

We have previous identified and functionally verified key PA biosynthesis structural genes TcANR, TcANS and TcLAR [37]. A scan of the promoter sequences in the PALACE database [39] of these PA synthesis genes revealed several target motifs of Myb transcription factors on each of them (Additional file 1: Figure S2). Interestingly, MYBCORE, the key cis-regulatory element for binding PA synthesis regulating Myb transcription factors [40], was found in all of them, suggesting that they could all be downstream targets of the putative $T c-M Y B P A$. To assess the involvement of $T c$ $M Y B P A$ in PA biosynthesis, the expression of the putative $T c-M Y B P A$ gene was examined in tissue samples from different developmental stages of leaves, flowers and pods in which PAs accumulate. In addition, the expression of the cacao PA biosynthesis structural genes TcANR, TcANS and TcLAR were also examined.

A strong positive correlation of expression levels of the putative Tc-MYBPA and the structural genes was observed in all tissues. The steady state levels of Tc-MYBPA, TcANR, TCANS and TcLAR transcripts were highest in young leaves and decreased in older leaves (Fig. 3a). Relatively high levels were present in flower tissues. We also measured the accumulation of total soluble PAs (including PA polymers as well as monomers) and insoluble PAs in the different tissues by DMACA assay and butanol- $\mathrm{HCl}$ assay respectively (described in details in Methods). Both cacao leaves and flowers contained significant levels of PAs. The highest total soluble PAs were detected in the youngest leaves (about $30 \mathrm{mg}$ procyanidin B2 equivalent/g fresh weight (FW), Fig. 3b). Much lower amounts were detected in older leaves. Total insoluble PAs were relatively lower in young leaves and continued to increase as the leaves aged and became harder. Insoluble PAs reached their maximum level in lignified stage $\mathrm{E}$ leaves (about $1.2 \mathrm{mg}$ cyanidin equivalent/g FW, Fig. 3c). PA levels were also considerable in flowers, with higher soluble PAs levels observed in unopened flowers than in opened flowers, and the levels of the insoluble fraction relatively the same in the two stages of flower development (Fig. 3b, c).

Figure 3 shows both the expression patterns of Tc-MYBPA, TcANR, TcANS and TcLAR (Fig. 3a) and PA levels in whole cacao pods early in their development when the pods are too small to separate ovules and exocarp (Fig. 4b, c). The expression of both Tc-MYBPA and the three PA structural genes shared a similar pattern. Their expression was relatively high at two weeks after pollination (WAP) and remained high at 5 WAP, followed by a significant decrease at 6 WAP (Fig. 4a). Levels of soluble PAs were already close to maximum (approximately $18 \mathrm{mg}$ procyanidin $\mathrm{B} 2$ equivalent/g FW) at the earliest sampling time point (Fig. 4b), whereas insoluble PAs reached maximum levels at 3 WAP (Fig. 4c). 

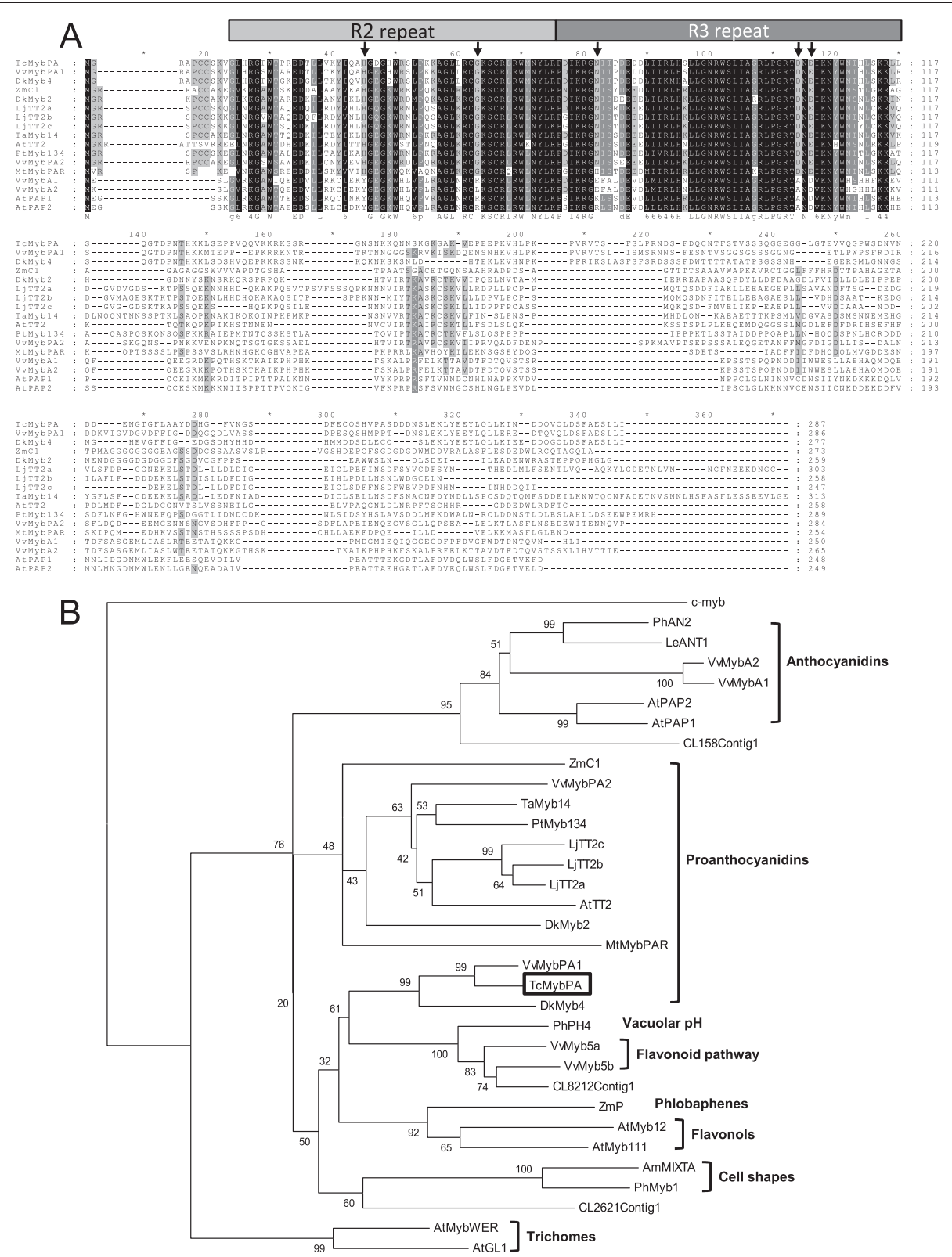

Fig. 2 Comparison of the amino acid sequences of TC-MYBPA and various plant MYB transcription factors. a Alignment of the deduced amino acid sequences of the R2R3-MYB proteins functioning in anthocyanin and PA synthesis, including Tc-MYBPA (cacao), ZmC1 (maize), VvMybPA1, VvMybPA2, VvMybA1, VvMybA2 (grape), PtMyb134 (poplar), LjTT2a, LjTT2b, LjTT2C (Lotus), and Arabidopsis regulators AtTT2, AtPAP1 and AtPAP2. The R2 and R3 repeats of the MYB domain are indicated above the alignment. Identical amino acids are indicated in black, similar amino acids in gray. Arrowheads indicate amino acids that are conserved in all PA-regulating MYBs but absent in anthocyanin-regulating MYBs. Sequences were aligned using the ClustalW program and were displayed using the GeneDoc program. b Phylogenetic tree showing selected plant MYB transcription factors from GenBank. Human c-myb is included as an outgroup. Functions of the MYB proteins are given on the right side in bold. The alignment was performed using the ClustalW program and the tree was constructed using the neighbor-joining algorithm of the MEGA package (Version 3.1). The scale bar represents 0.1 substitutions per site and the numbers next to each node are bootstrap values from 1000 replicates. The GenBank accession numbers of the MYB proteins are as follows: AtGL1 (P27900), ZmP (P27898), ZmC1 (AAA33482), VvMybA1 (BAD18977), VvMybA2 (BAD18978), AtPAP1 (AAG42001), PhAN2 (AAF66727), LeANT1 (AAQ55181), OsMyb4 (T02988), AmMixta (CAA55725), AtMyb111 (AAK97396), AtMyb12 (NM_130314), PmMybF1 (AAA82943), PhPH4 (AAY51377), AtPAP2 (AAG42002), AtMybWER (CAC01874), VvMyb5a (AAS68190), VvMYB5b (Q58QD0), VvMYBPA1 (AM259485), VvMybPA2 (ACK56131), C-myb (AAB49039), PtMyb134 (FJ573151), PhMyb1 (Z13996), LjTT2a (AB300033), LjTT2b (AB300034), LjTT2C (AB300035), AtTT2 (Q2FJA2), MtMybPAR (ADU78729), TaMyb14 (AFJ53053) Also included in the tree are one putative cacao PA specific MYB (TC-MYBPA), and three MYB-like proteins found in the cacao EST collections (CL158Contig1, CL8212Contig1 and CL2621Contig1) 
A
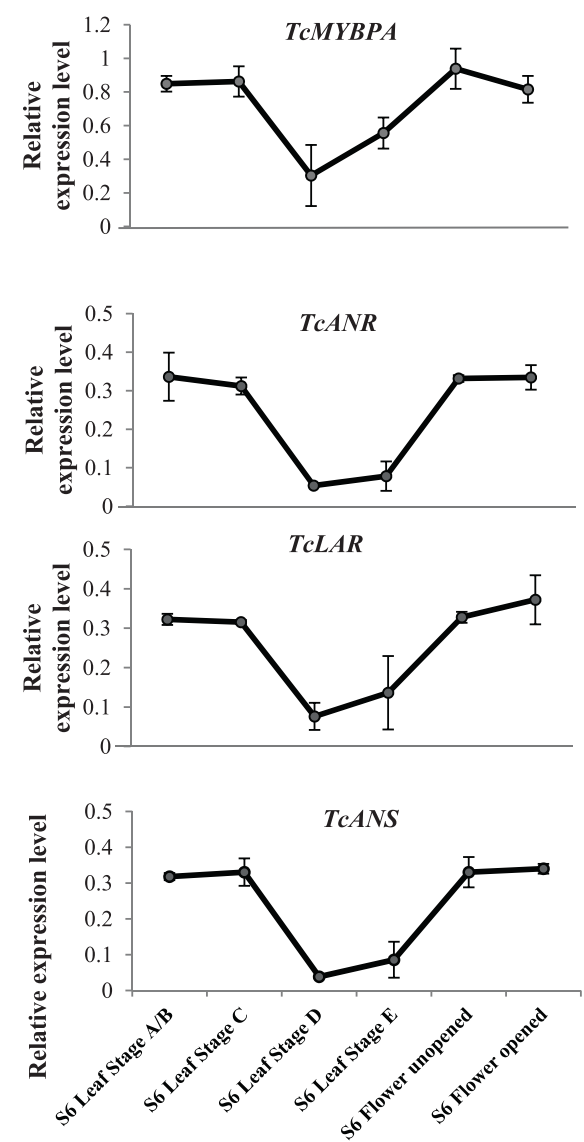

B
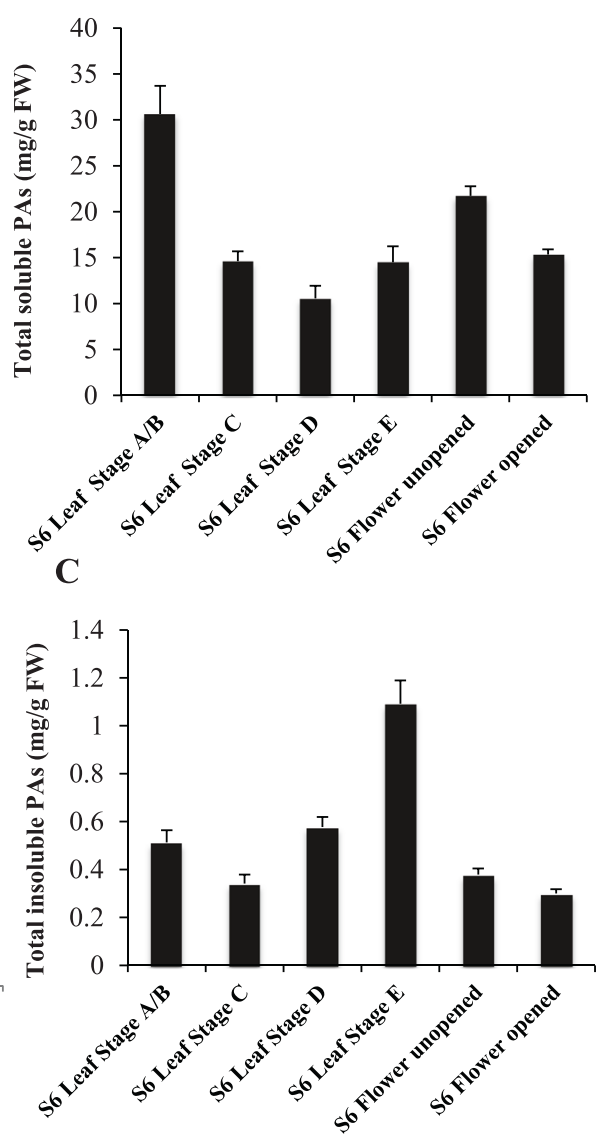

Fig. 3 Expression of TC-MYBPA, TCANR, TCANS and TCLAR genes and accumulation of PAs in Theobroma cacao (Scavina 6; S6) leaves and flowers at various developmental stages. a Transcript levels of TC-MYBPA, TCANR, TCANS and TCLAR. Expression was determined by semi-quantitative RT-PCR and was calculated relative to the expression of TcActin in each sample. $\mathbf{b}$ Levels of soluble PAs expressed as mg PA per $\mathrm{g}$ of fresh weight. $\mathbf{c}$ Levels of insoluble PAs expressed as mg PA per $g$ of fresh weight. All data are presented as means \pm SE, for gene expression data, $n \geq 3$, for $P A$ level data, $n \geq 5$. FW, Fresh weight

At 8 WAP, the pods were large enough to allow dissection into exocarp and ovule samples for separate analysis. Expression patterns of Tc-MYBPA, TcANR, TcANS and TcLAR genes and PA levels in cacao pod exocarp tissues were examined at two-week intervals, from 8 WAP to 20 WAP, when pods fully ripened. The expression of all four genes examined was similar (Fig. 5a). They were all relatively high from 8 WAP to 14 WAP but decreased significantly at 16 WAP, increasing again at $18 \mathrm{WAP}$ and reaching a maximum at $20 \mathrm{WAP}$. In accordance with gene expression patterns, the deposition of both soluble and insoluble PAs continued to increase during the development of the pods, reaching a maximum (soluble PA at approximately $50 \mathrm{mg}$ procyanidin B2 equivalent/g FW; insoluble PA at approximately $2.5 \mathrm{mg}$ cyanidin equivalent/g FW) around the time of ripening (Fig. 5b, c), while a pause of the PA accumulation occurred at $16 \mathrm{WAP}$, at which time point, soluble PAs were about the same level as 14 WAP and insoluble PAs slightly decreased.
Unlike the co-regulated pattern of gene expression in exocarp, the expression pattern of Tc-MYBPA and TcANS differed quite significantly from that of TcANR and TCLAR in ovules (Fig. 6a). The expression of TCANR and TCLAR in ovules was quite similar, maintaining relatively high levels before 14 WAP but significantly decreasing at 16 WAP, then increasing at 18 WAP and dropping again at $20 \mathrm{WAP}$. The overall expression level of TcLAR was lower than that of TcANR. In contrast, neither Tc-MYBPA nor TcANS expression decreased at 16 WAP but remained relatively stable (0.7-1.2 relative to TcActin) throughout pod development, from 8 WAP to 20 WAP, although a slight increase did occur after 16 WAP followed by slight decrease at 20 WAP. The PA concentrations of both soluble and insoluble fractions in cacao ovules were lower than in exocarp (Fig. 6b, c). The ovule soluble PA accumulation was relatively low before 16 WAP and significantly increased at $16 \mathrm{WAP}$, reaching a maximum 
A
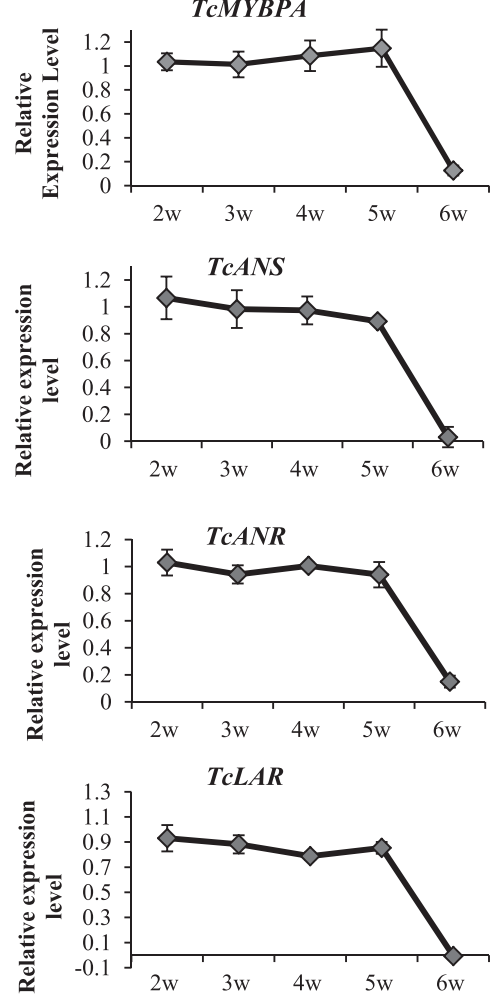

B

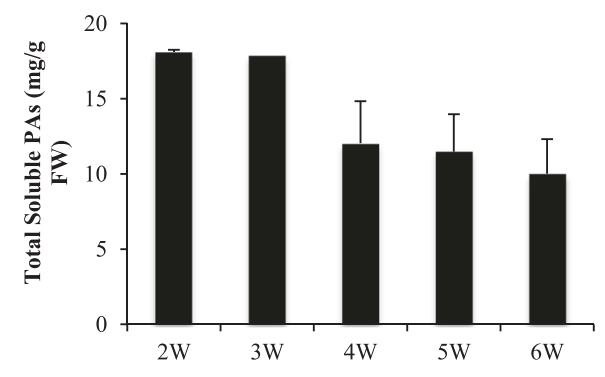

C

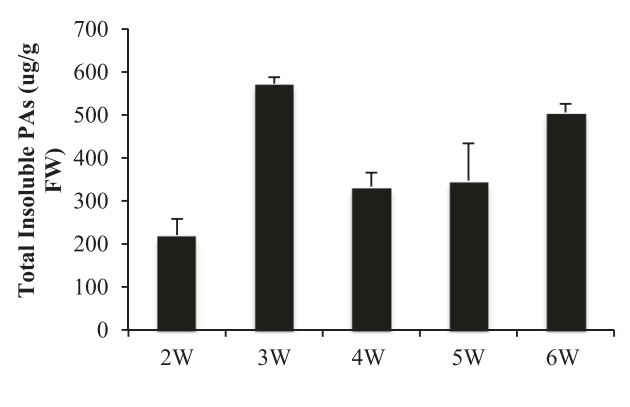

Fig. 4 Expression of TC-MYBPA, TCANR, TCANS and TCLAR genes and accumulation of PAs in whole pods of Theobroma cacao (Amelonado) during early stages of pod development (from 2 to 6 weeks after pollination). a Transcript levels of TCANR, TCANS and TCLAR. Expression was determined by semi-quantitative RT-PCR and was calculated relative to the expression of TCActin in each sample. $\mathbf{b}$ Levels of total soluble PAs expressed as mg PAs per $\mathrm{g}$ of fresh weight. $\mathbf{c}$ Levels of total insoluble PAs expressed as $\mu \mathrm{g}$ PAs per $\mathrm{g}$ of fresh weight. All data are presented as means \pm SE. For gene expression data, $n \geq 3$, for PA accumulation data, $n \geq 5$. FW, Fresh weight

at 20 WAP (about $35 \mathrm{mg}$ procyanidin B2 equivalent/g FW). However, throughout the development of ovules, insoluble PA levels increased at a relatively constant rate from 14 WAP.

The coordinated expression of Tc-MYBPA and TcANS suggest that $T c-M Y B P A$ may contribute to the regulation of anthocyanin synthesis as well as PA synthesis. Nevertheless, the regulation of the PA-specific genes TcANR and TCLAR may also involve other transcription factors such as bHLH and WD40 repeat proteins whose interactions with Tc-MYBPA determine their specific expression patterns, which are slightly different from TcANS. To gain a better understanding of their regulation, further characterization and expression analysis of $b H L H$ and WD40 genes will be helpful.

\section{Tc-MYBPA complements the PA-deficient phenotype of the Arabidopsis tt2 mutant}

Based on the very high degree of sequence conservation with Arabidopsis TT2 (see above) we hypothesized that the candidate gene Tc-MYBPA encodes a protein transcription factor that participates in the regulation of the PA biosynthesis genes LAR, ANR and LDOX. To test this hypothesis, a genetic complementation test was performed by introduction of a constitutively expressed $T c-M Y C P A$ coding sequence into the Arabidopsis $t t 2$ mutant [10], creating Tc-MYBPA-tt2 transgenic plants. Twenty one hygromycin-resistant transgenic T1 plants were generated and all of them developed a normal phenotype regarding general plant health, vigor, size and height. Three independent hygromycin-resistant transgenic T1 plants of Tc-MYBPA-tt2 were selected because of their increased seed coat color by visual observation. After staining with dimethylaminocinnamaldehyde (DMACA), a dye that can specifically interact with PAs and present a blue reaction product [41], 2 lines (Line 6 and Line 12) stained blue with DMACA (Fig. 7a), suggesting deposition of PAs in the seed coat. The other lines that did not develop an increased seed coat color also did not stain blue with DMACA (data not shown). In Line 6, the DMACA staining resulted in nearly the same intense color as in Col-0; while in line 12 , the blue color was less intense than in Col-0, suggesting decreased PA levels compared to wild-type. RTPCR using RNA extracted from T2 seedlings confirmed expression of the Tc-MYBPA gene in these transgenic 
A
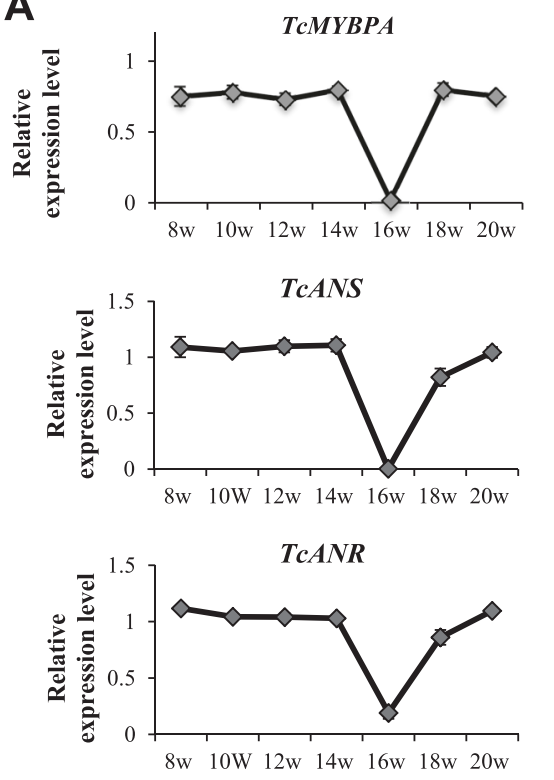

TcLAR

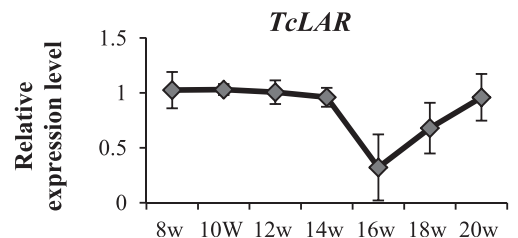

B

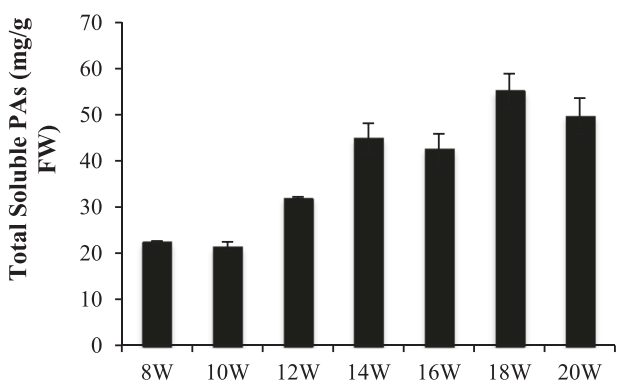

C

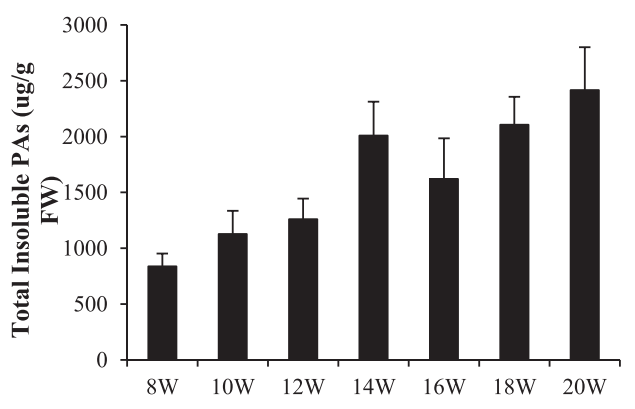

Fig. 5 Expression of TC-MYBPA, TCANR, TCANS and TCLAR genes and accumulation of PAs in pod exocarp of Theobroma cacao (Amelonado) during pod development (from 8 to 20 weeks after pollination). a Transcript levels of TC-MYBPA, TCANR, TCANS and TCLAR. Expression was determined by semi-quantitative RT-PCR and was calculated relative to the expression of TCActin in each sample. $\mathbf{b}$ Levels of total soluble PAs expressed as mg PAs per $\mathrm{g}$ of fresh weight. $\mathbf{c}$ Levels of total insoluble PAs expressed as $\mu \mathrm{g}$ PAs per $\mathrm{g}$ of fresh weight. All data are presented as means $\pm \mathrm{SE}$, for gene expression data, $n \geq 3$, for PA level data, $n \geq 5$. FW, Fresh weight

lines and indicated that Line 6 had the highest expression level, which correlated with the highest PA levels as suggested by DMACA staining (Fig. 7b). PA levels in the two Tc-MYBPA-tt2 lines were 2-8-fold higher than in the $t t 2$ background (Fig. 7c). Tc-MYBPA-tt2 line 6, which had the highest Tc-MYBPA expression, had nearly the same PA concentration as in the Col-0 seeds. In the young seedlings, two transgenic lines (Line 6 and Line 12) accumulated elevated levels of anthocyanins in the hypocotyls compared to $t t 2$ mutant plants. Line 6 , which has the highest Tc-MYBPA gene expression level, accumulated the most red/purple anthocyanin pigments.

In order to confirm that Tc-MYBPA activates PA synthesis genes, we used semi-quantitative RT-PCR to examine the expression of relevant genes in young seedlings of transgenic Tc-MYBPA-tt2 lines, untransformed tt2 mutant and wild-type plants (Fig. 8). Expression levels were measured for the PA-related structural genes (DFR, LDOX and BAN) as well as the general flavonoid pathway genes (chalcone synthase, $C H S$; chalcone isomerase, $\mathrm{CHI}$; and flavonoid 3'-hydroxylase, $F 3 H$ ), a flavonol-specific gene (flavonol synthase; FLS) and an anthocyanin-specific gene (UDP-Glc-flavonoid glucosyltransferase, UFGT). Gene expression of DFR and $L D O X$ was at about the same level as in the wild-type (Col-0) control and the $t t 2$ mutant, a result consistent with their contribution to anthocyanidin synthesis. In all transgenic lines, overexpression of $T c-M Y B P A$ was found to activate the flavonoid late biosynthesis genes [10] related to PA synthesis (DFR, $L D O X$ and $B A N)$. There was a 2 -fold increase of $D F R$ gene expression in all transgenic lines, and an approximate 1.5-1.7-fold increase of $L D O X$ gene expression. $B A N$ was not expressed in either $t t 2$ or Col0 seedlings but it was significantly activated in the transgenic lines, suggesting that $T c-M Y B P A$ controls its activation. However, no significant gene activation was detected for all the other flavonoid genes including $C H S$, $C H I, F 3 H$ representing the general flavonoid pathway, FLS representing the flavonol-specific pathway and UFGT representing the anthocyanin-specific pathway.

\section{Discussion}

In this study, amino acid sequence motifs specific to the PA-regulating clade of MYB transcription factors from 
A
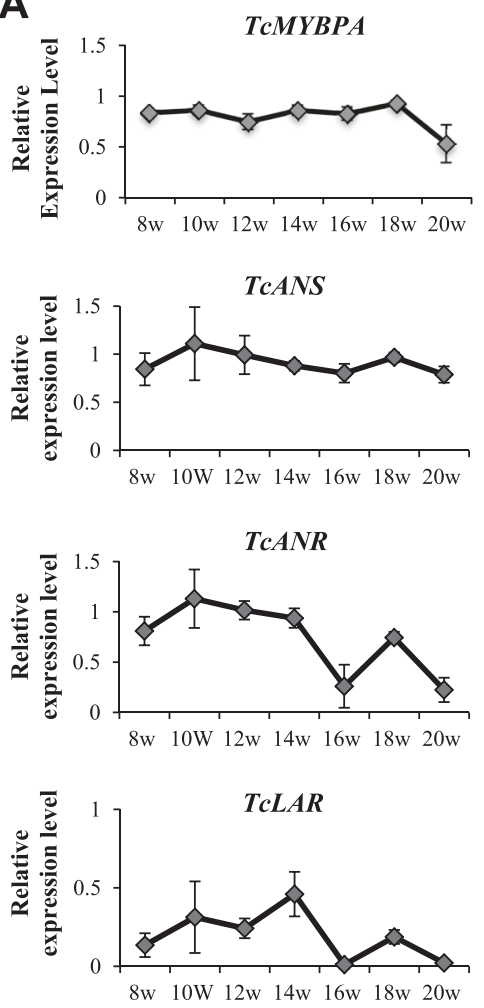

B

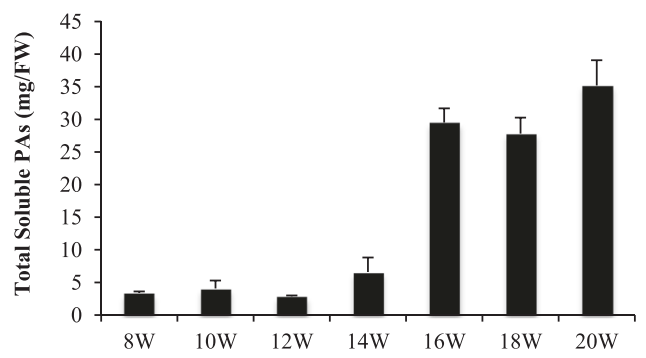

C

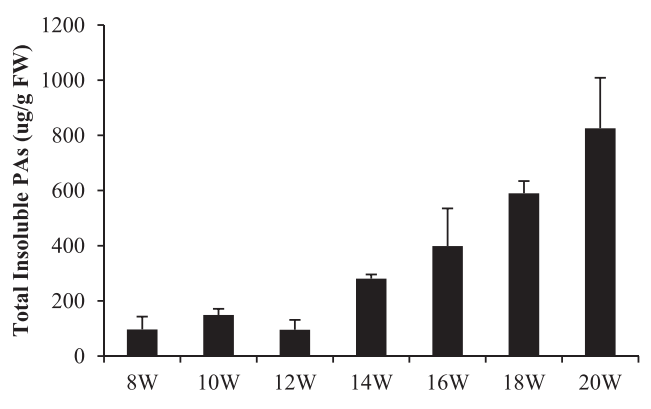

Fig. 6 Expression of TC-MYBPA, TCANR, TCANS and TCLAR genes and accumulation of PAs in ovules of Theobroma cacao (Amelonado) during pod development (from 8 to 20 weeks after pollination). a Transcript levels of TC-MYBPA, TCANR, TCANS and TCLAR. Expression was determined by semi-quantitative RT-PCR and was calculated relative to the expression of TCActin in each sample. $\mathbf{b}$ Levels of total soluble PAs expressed as mg PAs per $\mathrm{g}$ of fresh weight. $\mathbf{c}$ Levels of total insoluble PAs expressed as ug PAs per $\mathrm{g}$ of fresh weight. All data are presented as means \pm SE, for gene expression data, $n \geq 3$, for PA level data, $n \geq 5$. FW, Fresh weight

other species were used to identify a candidate cacao ortholog. We compared five genes from four species including Arabidopsis and Lotus TT2 [10, 20], grape VvMYBPA1 and VVMYBPA2 [23, 24] and poplar MYB134 [22]. Each of these has been experimentally demonstrated to play a key role in regulating the transcription of PA biosynthesis genes. Arabidopsis and Lotus TT2, poplar MYB134 and grape VvMYBPA2 formed a phylogenetic cluster with $\mathrm{ZmC1}$ from maize, which has been shown to activate the Arabidopsis $A N R$ promoter [10]. However, cacao Tc-MYBPA and grape VvMYBPA1 are not in the clade that contains most of the PA-regulating MYBs; they formed another cluster that is significantly closer to the TT2/C1 clade than to other functionally unrelated MYB regulators. By contrast, the multiple protein sequence alignment including all the known PA and anthocyanin-regulatory MYB proteins revealed some PA specific motifs in the N-terminal domain. Five sites ( 1 or 2 amino acids) were conserved in all PA-specific MYBs, including $\mathrm{ZmC1}$, but were absent from all other anthocyanin-specific MYBs. The discrepancy between the phylogenetic analysis, which showed a separate clade of Tc-MYBPA and VvMYBPA1 distinct from all other PA-regulatory MYBs, and the protein alignment, which clearly showed highly conserved PA-specific protein motifs in all PA MYBs, may result from the low homology C-terminal domain of those R2R3 MYB proteins. Similar to the results of Bogs et al. [23], none of the conserved motifs in the C-terminal domain described by Stracke et al. [19] were found. By contrast, phylogenic analysis seems to be a strong predictor of the anthocyanin regulatory MYB proteins, with all the functionally proven anthocyanin specific MYB transcription factors falling into the same subgroup [15, 42-44]. Interestingly, grape and cacao also share the distinction, together with tea, of being commercial species containing the highest levels of PA in all commonly consumed foods [45].

The analysis of PA levels during leaf development revealed that PA synthesis in cacao leaves occurs at higher levels in young leaves then in older leaves. This correlates with the synthesis of anthocyanins, which are present at a much higher concentrations in younger stage leaves than in mature leaves [46]. Anthocyanin and PA synthesis share common structural enzymes in the PA synthesis pathway, including anthocyanin synthase (ANS/LDOX), which produces cyanidins used in the 

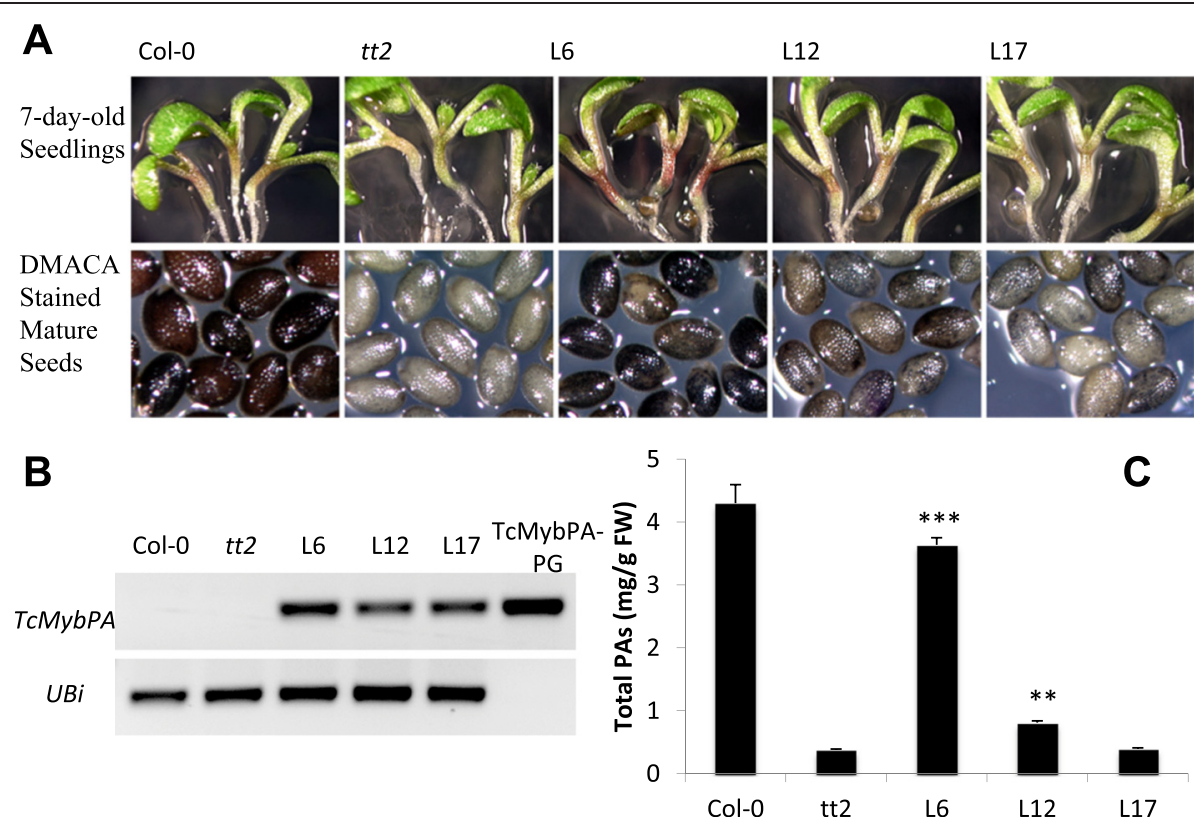

Fig. 7 Complementation of the PA-deficient tt2 mutant phenotype by constitutively expressing TC-MYBPA. a 7-day old seedlings of and DMACA stained seeds from Col-0, the tt2 mutant (SALK_005260) and three independent T2 transgenic lines of tt-35S:Tc-MYBPA. The bar represents 1 mm. b RT-PCR analysis of TC-MYBPA and AtUbiquitin transcripts in total RNA from the young seedlings shown in (a). PCR products from the TC-MYBPApGEM plasmid were loaded on the last lane as a positive control for the TC-MYBPA primer set and as a negative control for the AtUbiquitin primer set. C, PA levels in mature seeds of plants shown in (a). PA levels were determined by extraction and DMACA reaction using procyanidin B2 as a standard. All the data are presented as means $\pm \mathrm{SE}, \mathrm{n}=3$. ${ }^{* *} \mathrm{P}<0.01$ versus $t \mathrm{t} 2 ;{ }^{* * *} \mathrm{P}<0.001$ versus $t \mathrm{t} 2$. FW, fresh weight

ANR reaction leading to epicatechins and in the UFGT reaction leading to anthocyanidins. Consistent with the PA and anthocyanin accumulation patterns, the cacao PA-specific structural genes ANR and LAR and the anthocyanin PA-common gene ANS were all co-regulated in developing leaves and more highly expressed in younger leaves compared to older leaves. Expression of the TcMYBPA gene correlated well with PA accumulation rates and expression of the PA biosynthetic genes TcANR, TcANS and TcANR. Similar results were observed from $T c-M Y B P A$ transcript profiling in young pods and exocarp tissues, in which Tc-MYBPA exhibits the exactly same pattern with the co-regulated PA synthesis genes TcANR, $T c A N S$ and TcANR, suggesting that the Tc-MYBPA protein is involved in regulation of PA biosynthesis in leaves, young pods and exocarp.

In cacao reproductive tissues, PA synthesis began in developing flowers prior to pollination and continued in fruits until maturation, while anthocyanin synthesis began at the onset of fruit ripening and paralleled PA synthesis until maturation. Distinct from co-regulated expression of TcANS, TcANR and TcLAR genes in fruit exocarp, the TcANS gene had a different expression pattern from that of TcANR and TcLAR in ovules. TcANR and TcLAR were still co-regulated in ovules throughout developmental stages and both dropped at 16 WAP when fruit ripening commences and anthocyanin synthesis begins, while TcANS expression remained relatively high at 16 WAP, likely contributing to anthocyanin synthesis. Surprisingly, Tc-MYBPA shared the same expression pattern with TcANS rather than with the PA-specific genes TcANR and TCLAR, and the expression level remained stable, showing no decrease at 16 WAP. Similar observations were observed regarding the expression pattern of $V v M Y B P A 1$ in grape skins, in which $V v M Y B P A 1$ retained a relatively high transcript level two weeks after the onset of ripening and PA synthesis completely stopped when anthocyanin synthesis began [23]. One interpretation is that the high levels of $V v M Y B P A 1$ could also contribute to anthocyanin synthesis, as it could activate the promoter of the $V v A N S(V v L D O X)$ gene. Overall, the expression pattern of Tc-MYBPA suggests that the encoded protein is involved in regulation of PA biosynthesis; moreover, it may also be involved in regulation of anthocyanin biosynthesis.

Overexpression of $T c-M Y B P A$ in the Arabidopsis $t t 2$ mutant complemented the PA-deficient phenotype in Arabidopsis mature seeds (Fig. 6). This indicated that this R2R3-type MYB transcription factor was able to substitute for the function of the key Arabidopsis PA regulator TT2. In contrast to grape VvMYBPA1 (the MYB protein most similar to Tc-MYBPA1), which can induce ectopic PA accumulation when overexpressed in Arabidopsis, Tc-MYBPA-tt2 transgenic plants accumulated PAs only in the seed coat. This tissue specific 


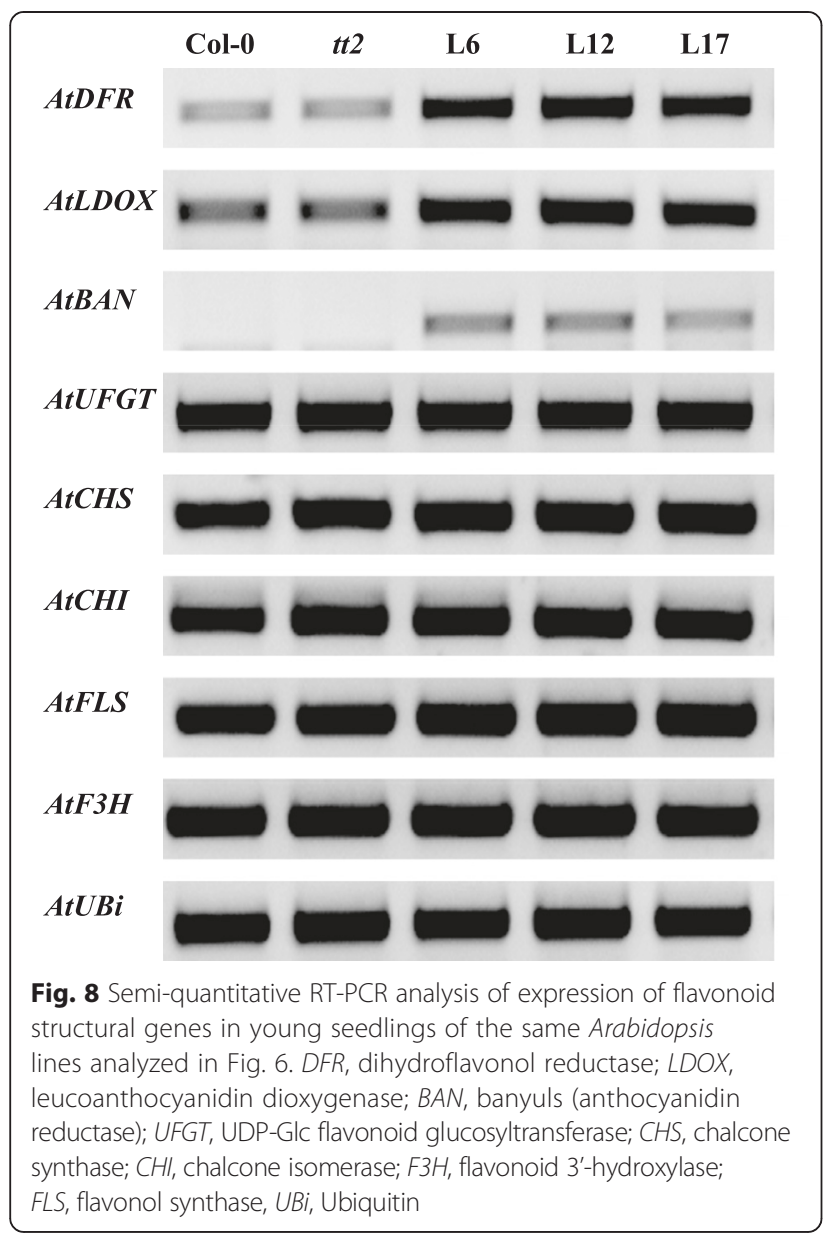

phenotype was similar to Arabidopsis TT2, which also failed to induce PA accumulation in tissues other than seed coat when ectopically expressed. Gene expression analysis of $T c-M Y B P A-t t 2$ transgenic plants showed that overexpression of $T c-M Y B P A$ induced only late flavonoid biosynthetic genes, DFR, $L D O X$ and $B A N$, similar to Arabidopsis TT2, which also controls only the late flavonoid biosynthetic genes DFR and BAN [10]. By contrast, VvMYBPA1 regulates the entire flavonoid pathway branch leading to PA synthesis, including both early and late flavonoid biosynthetic genes [23].

In transgenic Arabidopsis expressing the Tc-MYBPA gene, an increased accumulation of anthocyanins was also observed in hypocotyls of young seedlings; especially in Line 6, which showed an obvious visual color difference compared to untransformed controls. This could be explained by the ability of Tc-MYBPA to induce the expression of $L D O X(A N S)$, which is a structural gene contributing to both the anthocyanin and the proanthocyanin pathway. This is different from the Arabidopsis TT2 MYB transcription factor, which has been shown to involved specifically in the genetic control of flavonoid late biosynthesis genes (LBGs) including DFR, $L D O X$ and BAN only in seeds [10]. However, both $B A N$ and TT2 are not expressed in seedlings, while both DFR and LDOX are expressed in seedlings, contributing to anthocyanin synthesis. Their expression is controlled by another MYB transcription factor, AtPAP1 [47-49], whereas over-expression of AtTT2 did not increase the expression levels of LBGs in seedlings, with the exception of $B A N$, suggesting its specific involvement in PA synthesis [10]. The activity of Tc-MYBPA was in contrast to grape VvMYBPA1. Although VvMYBPA1 could activate the $V v L D O X$ gene promoter in transient reporter gene assays, it failed to induce anthocyanin synthesis when overexpressed in Arabidopsis [23]. Bogs et al. also showed that anthocyanin synthesis in grape was regulated by another MYB transcription factor VvMYBA2 [50]. However, the data from this research in transgenic Arabidopsis demonstrated that activation of anthocyanin synthesis was consistent with the Tc-MYBPA gene expression pattern in cacao, which was co-regulated with the TcANS gene and coincided with anthocyanin synthesis. Taken together, in cacao, Tc-MYBPA appeared to be capable of regulating both the PA and anthocyanin pathway by activating late PA biosynthetic genes. Potentially, this could provide a means to manipulate the amount and composition of PAs and anthocyanin together in cacao and possibly in other fruits. The different activities of the related MYB transcription factor genes from diverse species could reflect the evolutionary specialization of duplicated gene family members which appears to have taken slightly different functions over evolutionary time and can account in part for the differences in PA and anthocyanin accumulation patterns in these species.

\section{Conclusion}

In summary, our results support the conclusion that Tc-MYBPA from cacao is involved in regulation of transcription of several PA biosynthesis genes. This is based on several lines of evidence. First, protein sequence comparison showed that Tc-MYBPA was most similar to the grape PA transcriptional regulator VvMYBPA1 and shared the conserved motifs of all the other functionally characterized R2R3-MYB PA synthesis regulators. Second, transcript profiling showed that Tc-MYBPA was expressed in all tissues accumulating PAs and consistently co-regulated with PA biosynthesis structural genes including TcANR, TCANS and TcLAR. Third, over-expression of Tc$M Y B P A$ in Arabidopsis was able to functionally complement the PA-deficient phenotype in the seeds of 
the $t t 2$ mutant and resulted in a significant increase of PA accumulation compared to the $t t 2$ mutant. This was the result of activation of the PA biosynthetic genes including DFR, LDOX and $A N R$ as shown by gene expression analysis of transgenic plants relative to untransformed $t t 2$ and Col-0 plants.

\section{Methods}

\section{Plant material}

Two Theobroma cacao varieties: Scavina 6 and Amelonado were used for this study. Cacao plants were grown in greenhouse as previously described [51]. Leaf and flower tissues were collected from Scavina 6 plants. For leaf tissues, various stage leaves were collected. The definition of leaves stages were previously described [52], briefly, Stage A leaves are newly emerged and are $5-10 \mathrm{~cm}$ long; stage B leaves are larger, soft, red and translucent, $10-15 \mathrm{~cm}$ long; Stage C leaves are green and remain soft; Stage D leaves are at an early stage of lignification; Stage E leaves are fully lignified and mature. Stage A and B leaves were pooled together because of the limited amount of Stage A leaves. Cacao pods were obtained by hand pollinating Amelonado (a self-compatible variety). Upon harvesting, pods were bisected, and seeds and pod exocarps collected separately. Exocarp samples represent the outer 1-3 $\mathrm{mm}$ layer of the fruit obtained using a fruit peeler. All samples were frozen in liquid nitrogen upon collection and stored at $-80{ }^{\circ} \mathrm{C}$ until extraction.

Arabidopsis plants (Arabidopsis thaliana) were grown in soil at $22{ }^{\circ} \mathrm{C}, 50 \%$ humidity and a $16 \mathrm{~h} /$ $8 \mathrm{~h} \mathrm{light/dark}$ photoperiod in a growth chamber (Conviron, Pembina, ND, USA). Plants grown aseptically were plated on MS medium [53] with $2 \%$ (w/ v) sucrose solidified with $0.6 \%(\mathrm{w} / \mathrm{v})$ agar. Arabidopsis ecotype Columbia (Col-0) plants were used as the wild type. T-DNA insertion mutant tt2 (SALK_005260) were obtained from The Arabidopsis Biological Resource Center (Columbus, OH, USA).

\section{Isolation of a TC-MYBPA cDNA from Theobroma cacao}

Total RNA from stage A/B leaves of Theobroma cacao (Scavina 6) was isolated using a modified cetyl trimethyl ammonium bromide (CTAB) extraction method as previously described [54] with the following modifications. RNA isolated from the CTAB extraction and $\mathrm{LiCl}$ precipitation was further purified and concentrated using RNeasy columns (Qiagen, Valencia, CA, USA), but the phenol/chloroform extraction and sodium acetate/ehanol precipitation steps were omitted. The quality of RNA was verified by observing absorbance ratios of A260/A280 (1.8-2.0) and A260/A230 (1.8-2.2) and by separating 200 ng RNA samples on $0.8 \%$ agarose gels to examine intact ribosomal bands.

First strand cDNA was synthesized using the SMART RACE cDNA amplification kit (Clontech, Mountain View, CA, USA). The putative EST sequence of Tc-MYBPA was obtained by searching the Theobroma cacao EST database (http:/esttik.cirad.fr/ ) [34] using BLAST (program: tBLASTn) [55] with the protein sequence of TT2 (AT5G35550) from Arabidopsis thaliana as the query sequence. The ORF of putative Tc-MYBPA was amplified with the Advantage cDNA PCR Kit (Clontech, Mountain View, CA, USA) using CDNA from stage $\mathrm{A} / \mathrm{B}$ leaves as template with the following primer pairs: Tc-MYBPA_F (5'- GTCCATGGGAAGGGCTCCTTGTTGTTC -3') and Tc-MYBPA_R (5'AGCGGCCGCTCAGATCAATAATGATTCAGC -3'). To facilitate the subsequent cloning into binary vectors, an NcoI site (CCATGG) was added at the start codon (ATG) and a NotI site (GCGGCCGC) was added immediately $3^{\prime}$ to the stop codon (TCA) respectively (sites are shown in italics and the start or stop codons are underlined). The PCR reaction was carried out in a total volume of $20 \mu \mathrm{L}$ at $94{ }^{\circ} \mathrm{C}$ for $5 \mathrm{~min}$; 5 cycles of $94{ }^{\circ} \mathrm{C}$ for $30 \mathrm{~s}, 55^{\circ} \mathrm{C}$ for $30 \mathrm{~s}$, and $72{ }^{\circ} \mathrm{C}$ for $1 \mathrm{~min}$; another 23 cycles of $94{ }^{\circ} \mathrm{C}$ for $30 \mathrm{~s}$, $60{ }^{\circ} \mathrm{C}$ for $30 \mathrm{~s}$, and $72{ }^{\circ} \mathrm{C}$ for $1 \mathrm{~min}$; followed by a final extension at $72{ }^{\circ} \mathrm{C}$ for $5 \mathrm{~min}$. The PCR products were gel purified and cloned into the pGEM-T Easy plasmid (Promega, Madison, WI, USA) and replicated in E. coli strain DH5 $\alpha$. DNA sequencing was performed using 12 of the resulting DNA clones (pGEMT-Tc-MYBPA), and two clones had the precise sequence of the consensus sequences. One clone (pGEMT-Tc-MYBPA-3) was chosen for cloning into the binary vector for plant transformation and subsequent experiments.

\section{Protein sequence alignment and phylogenetic analysis}

PA-specific R2R3-MYB protein sequences were retrieved from GenBank (http://www.ncbi.nlm.nih.gov/Genbank/), including AtTT2 from Arabidopsis (CAC40021) [10], VvMYBPA1 and VvMYBPA2 from grape (AM259485, ACK56131) [23, 24], LjTT2a, LjTT2b and LjTT2c from Lotus japonicus (AB300033, AB300034, AB300035) [21] and MYB134 from Populus tremuloides (FJ573151) [22]. A protein sequence alignment performed with the ClustalW algorithm was used to construct a phylogenetic tree using the neighbor-joining method in the MEGA package [56]. One thousand bootstrap datasets were used to estimate the confidence of each tree clade. Protein sequence alignment of anthocyanin- and proanthocyaninspecific MYB proteins was performed using the same method as was for the phylogenetic tree but was edited and displayed using GENEDOC software (Version 2.6.02, http://www.nrbsc.org/gfx/genedoc/gddl.htm). 


\section{Proanthocyanidin (PAs) quantification}

To extract soluble PAs from cacao tissues, 0.3-0.5 g of frozen tissues were ground into a fine powder in liquid nitrogen and then extracted with $5 \mathrm{~mL}$ of extraction solution (70 \% acetone: $29.5 \%$ water: $0.5 \%$ acetic acid) by vortexing for $5 \mathrm{~s}$ followed by water bath sonication for 15 min using a bench top ultrasonic cleaner (Model 2510, Bransonic, Danbury, CT, USA). To extract soluble PAs from Arabidopsis seeds, the same extraction solution and method were applied, except that 100-500 mg dry seeds were used as grinding samples, and $500 \mu \mathrm{L}$ extraction solution were used. After sonication, samples were vortexed again and centrifuged at $2500 \mathrm{~g}$ for $10 \mathrm{~min}$. The supernatant was transferred to a new tube and the pellet was re-extracted twice as above. Pooled supernatants were extracted twice with hexane to remove fat and chlorophyll and then filtered through a $0.45 \mu \mathrm{m}$ polytetrafluoroethylene (PTFE) syringe filter (Millipore, Billerica, MA, USA). Depending on availability of plant samples, different numbers of biological replicates were performed for cacao and Arabidopsis samples. For cacao, there were at least five biological replicates, and for Arabidopsis, there were three biological replicates.

To quantify PA levels, $50 \mu \mathrm{L}$ aliquots of samples were mixed with $200 \mu \mathrm{L}$ of dimethylaminocinnamaldehyde (DMACA; Sigma-Aldrich, MO, USA) reagent (0.1\% DMACA, $90 \%$ reagent-grade ethanol, $10 \%$ $\mathrm{HCl}$ ) in 96-well microtiter plates. Absorption was measured at $640 \mathrm{~nm}$ at one-minute intervals for $20 \mathrm{~min}$, and the mean value of peak readings during this time period was recorded. For each biological replicate, triple technical replicates were performed to obtain mean values. The total PA levels were calculated using a standard molar absorbance curve prepared using procyanidin B2 (Indofine, NJ, USA).

For quantitative analysis of insoluble PAs from cacao tissues, the residues from soluble PA extractions were air dried in an exhaust hood for two days, weighed, and $5 \mathrm{~mL}$ butanol- $\mathrm{HCl}$ reagent $(95 \%$ butan-1-ol: $5 \%$ concentrated $\mathrm{HCl}$ ) was added and the mixture was sonicated for one hour followed by centrifugation at $2500 \mathrm{~g}$ for $10 \mathrm{~min}$. An aliquot of clear supernatant was diluted 40-fold in butanol- $\mathrm{HCl}$ reagent and absorbance was measured at $550 \mathrm{~nm}$ to determine the amount of background absorption. The samples were then boiled for $1 \mathrm{~h}$ with vortexing every $20 \mathrm{~min}$, cooled to room temperature and centrifuged again at $2500 \mathrm{~g}$ for $10 \mathrm{~min}$. The supernatant from boiled sample was diluted 40-fold in butanol$\mathrm{HCl}$ reagent and absorbance was measured at $550 \mathrm{~nm}$. The values were normalized by subtraction of the background absorbance and the PA levels were calculated as cyanidin equivalents using cyanidin-3glucoside (Sigma-Aldrich, MO, USA) as standards.

To visualize the presence of PAs in Arabidopsis young seedlings and dry seeds, tissues were immersed in 4dimethylaminocinnamaldehyde (DMACA) reagent $(2 \%$ (w/v) DMACA, $90 \%$ ethanol, $10 \% \mathrm{HCl}$ ) for 2 days as described previously [9] and then washed 3 times with $70 \%$ ethanol.

\section{Transformation of Arabidopsis}

The coding sequence of Tc-MYBPA was excised from the intermediate cloning vector (pGEMT-Tc-MYBPA3) with NcoI and NotI restriction enzymes and introduced into the pE2113-EGFP [51] intermediate vector to substitute the coding sequence of $T c$ $M Y B P A$ for the original EGFP coding sequence. As a result, the cacao gene coding sequence is located immediately downstream of the very strong E12- $\Omega$ promoter (a modified CaMV35S promoter) and upstream of the CaMV35S terminator. The overexpression cassette was excised out from pE2113 vector with EcorI and PvuII restriction enzymes and introduced into the pCAMBIA-1300 binary vector (CAMBIA, Canberra, Australia).

This binary transformation construct was introduced into Agrobacterium tumefaciens strain AGL1 [57] by electroporation as previously described [58]. Arabidopsis transformation was carried out using the floral dip method [59], and T1 transgenic plants were selected on MS media supplemented with $2 \%$ sucrose, $0.65 \%$ agar and $25 \mathrm{mg} / \mathrm{L}$ hygromycin. Hygromycinresistant $\mathrm{T} 1$ seedlings were transferred to soil 7 days after germination and grown in a growth chamber as described above.

\section{Gene expression analysis}

Total RNA from leaves, flowers, pods, pod exocarp and ovules of Theobroma cacao (Scavina 6 and Amelonado) was isolated as described above. Total RNA from young Arabidopsis seedlings was isolated using the RNeasy Plant mini kit (Qiagen, Valencia, CA, USA). cDNA was synthesized from $1 \mu \mathrm{g}$ of total RNA in a total volume of $20 \mu \mathrm{L}$ using M-MuLV Reverse Transcriptase (NEB, Ipswich, MA, USA) according to the supplier's protocols, and $2 \mu \mathrm{L}$ of this reaction were used in the subsequent RT-PCR reactions.

Semi-quantitative RT-PCR was performed to measure gene expression levels as previously described [60] with the following modifications: The primers for Arabidopsis cDNA span two exons, giving products of about $500 \mathrm{bp}$, and thus are mRNA specific, avoiding potential amplification from genomic DNA 
contamination. The primers sets used are listed in Table 1 below.

To ensure accurate semi-quantitative RT-PCR measurements, each primer set was tested in time course PCR reactions to measure amplification kinetics and to determine the optimal PCR cycle in which the reaction is well within the linear range (28 cycles). PCR reactions were carried out in a total volume of $20 \mu \mathrm{L}$ at $94{ }^{\circ} \mathrm{C}$ for $5 \mathrm{~min} ; 28$ cycles of $94{ }^{\circ} \mathrm{C}$ for $30 \mathrm{~s}, 55{ }^{\circ} \mathrm{C}$ for $30 \mathrm{~s}$, and $72{ }^{\circ} \mathrm{C}$ for $45 \mathrm{~s}$; followed by a final extension at $72{ }^{\circ} \mathrm{C}$ for $5 \mathrm{~min}$. The PCR products were visualized on $1 \%$ agarose gels stained with ethidium bromide and photographed using a Molecular Imager Gel Doc XR+ System equipped with a 16-bit CCD camera (Bio-Rad Laboratories, Hercules, CA). Relative fluorescent intensity of the separated PCR products was quantified using Quantity One 1D Analysis Software (Bio-Rad Laboratories, Hercules, CA). Expression levels were calculated relative to the expression of TcActin in each sample.
Availability of supporting data

The phylogenetic tree for the study have been submitted to DRYAD (doi:10.5061/dryad.57fc0).

\section{Additional file}

Additional file 1: Figure S1. Sequence analysis of other putative cacao T2 like genes. Figure S2. MYB-binding motifs in the promoters of cacao PA synthesis genes, TCANR, TCLAR, TCANS, transcription factor TCMybPA and Arabidopsis AtTT2 detected using the PLACE database (http://www.dna.affrc.go.jp/PLACE/signalup.html).

\section{Abbreviations}

PAs: Proanthocyanidins; DFR: Dihydroflavanol reductase; ANS: Anthocyanin synthase; LDOX: Leucoanthocyanidin dioxygenase; ANR: Anthocyanidin reductase; ORFs: Open reading frames; ESTs: Expressed sequence tags; DMACA: Dimethylaminocinnamaldehyde; WAP: Week after pollination.

\section{Competing interests}

The authors declare that they have no competing interests.

Table 1 Sequences of the primers used in the gene expression study

\begin{tabular}{|c|c|c|c|c|}
\hline Gene & Protein & Locus ID & Primer & Sequence $\left(5^{\prime}\right.$ to $\left.3^{\prime}\right)$ \\
\hline \multirow[t]{2}{*}{ ANS (LDOX) } & \multirow[t]{2}{*}{ leucoanthocyanidin dioxygenase } & \multirow[t]{2}{*}{ Tc03g026420 } & TCANS_RTF & ACCTTGTTAACCATGGGATCTCGG \\
\hline & & & TCANS_RTR & GACGGTGTCACCAATGTGCATGAT \\
\hline \multirow[t]{2}{*}{ ANR } & \multirow[t]{2}{*}{ anthocyanidin reductase } & \multirow[t]{2}{*}{ Tc06g018030 } & TCANR_RTF & TGCTTGAGAAGGGCTACGCTGTTA \\
\hline & & & TCANR_RTR & AAAGATGTGGCAAGGCCAATGCTG \\
\hline \multirow[t]{2}{*}{ LAR } & \multirow[t]{2}{*}{ Leucoanthocyanidin reductase } & \multirow[t]{2}{*}{ Tc03g002450 } & TCLAR_RTF & AATTCCATTGCAGCTTGGCCCTAC \\
\hline & & & TCLAR_RTR & GGCTTGCTCACTGCTTTGGCATTA \\
\hline \multirow[t]{2}{*}{ UB } & \multirow[t]{2}{*}{ polyubiquitin } & \multirow[t]{2}{*}{ Tc06g018641 } & TcUb_RTF & AGCTGAGAGATTCCGTTGTCCAGA \\
\hline & & & TcUb_RTR & CCCACATCAACCAGACTTTGAGTTC \\
\hline \multirow[t]{2}{*}{ MybPA } & \multirow[t]{2}{*}{ TT2 like MYB transcriptoin factor } & \multirow[t]{2}{*}{ Tc01g034240 } & TC-MYBPA_RTF & GATGGGAAGGGCTCCTTGTTG \\
\hline & & & TC-MYBPA_RTR & ATCTCGTTATCGGTTGGACCAG \\
\hline \multirow[t]{2}{*}{ DFR } & \multirow[t]{2}{*}{ dihydroflavonol 4-reductase } & \multirow[t]{2}{*}{ AT5G42800 } & AtDFR_RTF & CCGTGTGTGTAACCGGCGCT \\
\hline & & & AtDFR_RTR & TGCGCCTCGTTCCGAGTGAT \\
\hline \multirow[t]{2}{*}{ LDOX (ANS) } & \multirow[t]{2}{*}{ leucoanthocyanidin dioxygenase } & \multirow[t]{2}{*}{ AT4G22880 } & AtLDOX_RTF & CACCAAGTGATTACATAGAAGCAACG \\
\hline & & & AtLDOX_RTR & TCACCATCTCCGGCAACGGC \\
\hline \multirow[t]{2}{*}{ BAN (ANR) } & \multirow[t]{2}{*}{ anthocyanidin reductase } & \multirow[t]{2}{*}{ AT1G61720 } & AtBAN_RTF & TGGTGGCACGGGAAACTTAGCC \\
\hline & & & AtBAN_RTR & CGGTCACATGCATTTCTITCCCGGT \\
\hline \multirow[t]{2}{*}{ UFGT } & \multirow[t]{2}{*}{ UDP-glucosyl transferase } & \multirow[t]{2}{*}{ AT5G17050 } & AtUFGT_RTF & ACCATCGGTGTCAAAGAAGTAGGTG \\
\hline & & & AtUFGT_RTR & GCGGTGCCCATGGAACCACT \\
\hline \multirow[t]{2}{*}{$\mathrm{CHS}$} & \multirow[t]{2}{*}{ chalcone synthase } & \multirow[t]{2}{*}{ AT5G13930 } & AtCHS_RTF & TCAAGCGCATGTGCGACAAGT \\
\hline & & & AtCHS_RTR & CGGCGGCGCCATCACTGAAA \\
\hline \multirow[t]{2}{*}{$\mathrm{CHI}$} & \multirow[t]{2}{*}{ chalcone isomerase } & \multirow[t]{2}{*}{ AT3G55120 } & AtCHI_RTF & TCATCCAACGCCTGCGCCTC \\
\hline & & & AtCHI_RTR & ACGCAACCGTAAGAGAGCCGGT \\
\hline $\mathrm{F} 3 \mathrm{H}$ & flavanone 3-hydroxylase & AT3G51240 & AtF3H_RTF & ACCTCCAGGGAGAGGCTGTGC \\
\hline & & & AtF3H_RTR & AAATGGCCGTGGTCGCCGAG \\
\hline FLS & flavonol synthase 1 & AT5G08640 & AtFLS_RTF & ATCTGGCCACCGTCATGCGTC \\
\hline & & & AtFLS_RTR & ССТСССАTTACTCAACCTCAGAATC \\
\hline
\end{tabular}




\section{Authors' contributions}

$Y L$ performed most of the experiments, ie, sequence analysis, gene cloning, gene expression studies, transgenic Arabidopsis generation, phenotypic analysis of transgenic lines, and drafted the manuscript. ZS participated in gene expression analysis, transgenic Arabidopsis lines generation and analysis. SNM participated in the design of the study, directed the vector construction and drafting of the manuscript. MJP developed and directed PA quantification analysis. MJG conceived the study, drafted the manuscript and gave advice on experimental design, data analysis and execution. All authors read and approved the final manuscript.

\section{Acknowledgements}

We thank undergraduate students at The Pennsylvania State University: Fred Gouker for assistance with Tc-MYBPA cloning and Dennis Arocena for assistance with PA extraction. We appreciate the help from people in Guiltinan lab, especially Ann Young and Sharon Pishak for assistance with green house maintenance, tissue culture and cacao sample collection. This work is supported in part by The Pennsylvania State University, The Huck Institutes of Life Sciences and American Research Institute Penn State Endowed Program in the Molecular Biology of Cacao.

\section{Author details}

${ }^{1}$ Huck Institute of Life Sciences, The Pennsylvania State University, University Park, PA 16802, USA. ${ }^{2}$ Department of Horticulture, The Pennsylvania State University, 422 Life Sciences Building, University Park, PA 16802, USA. ${ }^{3}$ Hershey Center for Health and Nutrition, The Hershey Company, 1025 Reese Ave., Hershey, PA 17033, USA. ${ }^{4}$ Present address: Cellular \& Molecular Pharmacology, University of California, San Francisco, Mission Bay Campus, Genentech Hall, N576/Box 2280, 600 16th Street, San Francisco, CA 94158, USA.

Received: 28 January 2015 Accepted: 20 May 2015

Published online: 25 June 2015

\section{References}

1. Treutter D. Significance of flavonoids in plant resistance and enhancement of their biosynthesis. Plant Biol. 2005;7(6):581-91.

2. Norman $\mathrm{KH}$, Naomi DLF, Marjorie LM. Flavanols, the Kuna, cocoa consumption, and nitric oxide. J Am Soc Hypertens. 2009;3(2):105-12.

3. Xie DY, Dixon RA. Proanthocyanidin biosynthesis-still more questions than answers? Phytochemistry. 2005:66(18):2127-44

4. Winkel-Shirley B. It takes a garden. How work on diverse plant species has contributed to an understanding of flavonoid metabolism. Plant Physiol. 2001;127(4):1399-404.

5. Dixon RA, Pasinetti GM. Flavonoids and isoflavonoids: from plant biology to agriculture and neuroscience. Plant Physiol. 2010;154(2):453-7.

6. Lepiniec L, Debeaujon I, Routaboul JM, Baudry A, Pourcel L, Nesi N, et al. Genetics and biochemistry of seed flavonoids. Annu Rev Plant Biol. 2006;57:405-30.

7. Grotewold E. The genetics and biochemistry of floral pigments. Annu Rev Plant Biol. 2006;57:761-80.

8. Ramsay NA, Glover BJ. MYB bHLH WD40 protein complex and the evolution of cellular diversity. Trends Plant Sci. 2005;10(2):63-70.

9. Abrahams S, Tanner GJ, Larkin PJ, Ashton AR. Identification and biochemical characterization of mutants in the proanthocyanidin pathway in Arabidopsis. Plant Physiol. 2002;130(2):561-76.

10. Nesi N, Jond C, Debeaujon I, Caboche M, Lepiniec L. The Arabidopsis TT2 gene encodes an R2R3 MYB domain protein that acts as a key determinant for proanthocyanidin accumulation in developing seed. Plant Cell. 2001;13(9):2099-114.

11. Baudry A, Heim MA, Dubreucq B, Caboche M, Weisshaar B, Lepiniec L. TT2, TT8, and TTG1 synergistically specify the expression of BANYULS and proanthocyanidin biosynthesis in Arabidopsis thaliana. Plant J. 2004;39(3):366-80.

12. Grotewold E, Sainz MB, Tagliani L, Hernandez JM, Bowen B, Chandler VL. Identification of the residues in the Myb domain of maize $\mathrm{C} 1$ that specify the interaction with the bHLH cofactor R. Proc Natl Acad Sci USA. 2000;97(25):13579-84.

13. Allan AC, Hellens RP, Laing WA. MYB transcription factors that colour our fruit. Trends Plant Sci. 2008;13(3):99-102.
14. de Vetten N, Quattrocchio F, Mol J, Koes R. The an11 locus controlling flower pigmentation in petunia encodes a novel WD-repeat protein conserved in yeast, plants, and animals. Genes Dev. 1997;11(11):1422-34.

15. Quattrocchio F, Wing J, van der Woude K, Souer E, de Vetten N, Mol J, et al. Molecular analysis of the ANTHOCYANIN2 gene of petunia and its role in the evolution of flower color. Plant Cell. 1999;11(8):1433-44.

16. Spelt C, Quattrocchio F, Mol JN, Koes R. ANTHOCYANIN1 of petunia encodes a basic helix-loop-helix protein that directly activates transcription of structural anthocyanin genes. Plant Cell. 2000;12(9):1619-32.

17. Nesi N, Debeaujon I, Jond C, Pelletier G, Caboche M, Lepiniec L. The TT8 gene encodes a basic helix-loop-helix domain protein required for expression of DFR and BAN genes in Arabidopsis siliques. Plant Cell. 2000;12(10):1863-78.

18. Pelletier MK, Murrell JR, Shirley BW. Characterization of flavonol synthase and leucoanthocyanidin dioxygenase genes in Arabidopsis. Further evidence for differential regulation of "early" and "late" genes. Plant Physiol. 1997;113(4):1437-45.

19. Stracke R, Werber M, Weisshaar B. The R2R3-MYB gene family in Arabidopsis thaliana. Curr Opin Plant Biol. 2001;4(5):447-56.

20. Stracke R, Ishihara H, Huep G, Barsch A, Mehrtens F, Niehaus K, et al. Differential regulation of closely related R2R3-MYB transcription factors controls flavonol accumulation in different parts of the Arabidopsis thaliana seedling. Plant J. 2007:50(4):660-77.

21. Yoshida K, Iwasaka R, Kaneko T, Sato S, Tabata S, Sakuta M. Functional differentiation of Lotus japonicus TT2s, R2R3-MYB transcription factors comprising a multigene family. Plant Cell Physiol. 2008;49(2):157-69.

22. Mellway RD, Tran LT, Prouse MB, Campbell MM, Constabel CP. The wound-, pathogen-, and ultraviolet B-responsive MYB134 gene encodes an R2R3 MYB transcription factor that regulates proanthocyanidin synthesis in poplar. Plant Physiol. 2009;150(2):924-41.

23. Bogs J, Jaffe FW, Takos AM, Walker AR, Robinson SP. The grapevine transcription factor WMYBPA1 regulates proanthocyanidin synthesis during fruit development. Plant Physiol. 2007;143(3):1347-61.

24. Terrier N, Torregrosa L, Ageorges A, Vialet S, Verries C, Cheynier V, et al. Ectopic expression of VVMybPA2 promotes proanthocyanidin biosynthesis in grapevine and suggests additional targets in the pathway. Plant Physiol. 2009;149(2):1028-41.

25. Akagi T, Ikegami A, Yonemori K. DkMyb2 wound-induced transcription factor of persimmon (Diospyros kaki Thunb.), contributes to proanthocyanidin regulation. Planta. 2012;232(5):1045-59.

26. Hancock KR, Collette V, Fraser K, Greig M, Xue H, Richardson K, et al. Expression of the R2R3-MYB transcription factor TaMYB14 from Trifolium arvense activates proanthocyanidin biosynthesis in the legumes Trifolium repens and Medicago sativa. Plant Physiol. 2012;159(3):1204-20.

27. Verdier J, Zhao J, Torres-Jerez I, Ge S, Liu C, He X, et al. MtPAR MYB transcription factor acts as an on switch for proanthocyanidin biosynthesis in Medicago truncatula. Proc Natl Acad Sci U S A. 2012;109(5):1766-71.

28. Keen CL, Holt RR, Polagruto JA, Wang JF, Schmitz HH. Cocoa flavanols and cardiovascular health. Phytochem Rev. 2002;1:231-40.

29. Niemenak N, Rohsius C, Elwers S, Ndoumou DO, Lieberei R. Comparative study of different cocoa (Theobroma cacao L.) clones in terms of their phenolics and anthocyanins contents. J Food Comp Anal. 2006;19 $(6-7): 612-9$.

30. Wright DC, Park WD, Leopold NR, Hasegawa PM, Janick J. Accumulation of lipids, proteins, alkaloids and anthocyanins during embryo development in vivo of Theobroma cacao L. J Am Oil Chem Soc. 1982;59(11):475-9.

31. Alemanno L, Berthouly M, Michaux Ferriere N. A comparison between Theobroma cacao L. zygotic embryogenesis and somatic embryogenesis from floral explants. In Vitro Cell Dev Biol Plant. 1997;33(3):163-72.

32. Cheesman EE. Fertilization and embryogeny in Theobroma cacao. L Ann Bot 1927:41(161):107-26.

33. Lehrian DW, Keeney PG. Changes in lipid components of seeds during growth and ripening of cacao fruit. J Am Oil Chem Soc. 1980;57(2):61-5.

34. Argout X, Fouet $O$, Wincker $P$, Gramacho K, Legavre T, Sabau X, Risterucci AM, Da Silva C, Cascardo J, Allegre M, et al. Towards the understanding of the cocoa transcriptome: Production and analysis of an exhaustive dataset of ESTs of Theobroma cacao $L$. generated from various tissues and under various conditions. BMC genomics. 2008;9:512.

35. Chaves FC, Gianfagna TJ. Cacao leaf procyanidins increase locally and systemically in response to infection by Moniliophthora perniciosa basidiospores. Physiol Mol Plant Pathol. 2007;70(4-6):174-9. 
36. Argout X, Salse J, Aury JM, Guiltinan MJ, Droc G, Gouzy J, et al. The genome of Theobroma cacao. Nat Genet. 2011:43(2):101-8.

37. Liu Y, Shi Z, Maximova S, Payne MJ, Guiltinan MJ. Proanthocyanidin synthesis in Theobroma cacao: genes encoding anthocyanidin synthase, anthocyanidin reductase, and leucoanthocyanidin reductase. BMC plant biology. 2013;13:202

38. Czemmel S, Stracke R, Weisshaar B, Cordon N, Harris NN, Walker AR, et al. The grapevine R2R3-MYB transcription factor VVMYBF1 regulates flavonol synthesis in developing grape berries. Plant Physiol. 2009;151(3):1513-30.

39. Higo K, Ugawa Y, Iwamoto M, Korenaga T. Plant cis-acting regulatory DNA elements (PLACE) database: 1999. Nucleic Acids Res. 1999;27(1):297-300.

40. Akagi T, Ikegami A, Tsujimoto T, Kobayashi S, Sato A, Kono A, et al. DkMyb4 is a Myb transcription factor involved in proanthocyanidin biosynthesis in persimmon fruit. Plant Physiol. 2009;151(4):2028-45.

41. McMurrough I, McDowell J. Chromatographic separation and automated analysis of flavanols. Anal Biochem. 1978;91(1):92-100.

42. Mathews H, Clendennen SK, Caldwell CG, Liu XL, Connors K, Matheis N, et al. Activation tagging in tomato identifies a transcriptional regulator of anthocyanin biosynthesis, modification, and transport. Plant Cell. 2003;15(8):1689-703.

43. Deluc L, Barrieu F, Marchive C, Lauvergeat V, Decendit A, Richard T, et al. Characterization of a grapevine R2R3-MYB transcription factor that regulates the phenylpropanoid pathway. Plant Physiol. 2006;140(2):499-511.

44. Deluc L, Bogs J, Walker AR, Ferrier T, Decendit A, Merillon JM, et al. The transcription factor VVMYB5b contributes to the regulation of anthocyanin and proanthocyanidin biosynthesis in developing grape berries. Plant Physiol. 2008;147(4):2041-53.

45. U.S. Department of Agriculture, Agricultural Research Service. 2014. USDA National Nutrient Database for Standard Reference, Release 27. Nutrient Data Laboratory Home Page, http://www.ars.usda.gov/ba/bhnrc/ndl

46. Lee DW, Brammeier S, Smith AP. The selective advantages of anthocyanins in developing leaves of mango and cacao. Biotropica. 1987;19(1):40-9.

47. Dare AP, Schaffer RJ, Lin-Wang K, Allan AC, Hellens RP. Identification of a cis-regulatory element by transient analysis of co-ordinately regulated genes. Plant Methods. 2008;4:17.

48. Cominelli E, Gusmaroli G, Allegra D, Galbiati M, Wade HK, Jenkins Gl, et al. Expression analysis of anthocyanin regulatory genes in response to different light qualities in Arabidopsis thaliana. J Plant Physiol. 2008;165(8):886-94.

49. Borevitz JO, Xia Y, Blount J, Dixon RA, Lamb C. Activation tagging identifies a conserved MYB regulator of phenylpropanoid biosynthesis. Plant Cell. 2000;12(12):2383-94

50. Walker AR, Lee E, Bogs J, McDavid DA, Thomas MR, Robinson SP. White grapes arose through the mutation of two similar and adjacent regulatory genes. Plant J. 2007;49(5):772-85.

51. Maximova S, Miller C, Antunez de Mayolo G, Pishak S, Young A, Guiltinan MJ. Stable transformation of Theobroma cacao $L$. and influence of matrix attachment regions on GFP expression. Plant Cell Rep. 2003;21(9):872-83.

52. Liu Y: Molecular analysis of genes involved in the synthesis of proanthocyanidins in theobroma cacao. PhD Dissertation. Univesity Park: The Pennsylvania state university; 2010

53. Murashige T, Skoog F. A revised medium for rapid growth and bio assays with tobacco tissue cultures. Physiol Plant. 1962;15(3):473-97.

54. Verica JA, Maximova SN, Strem MD, Carlson JE, Bailey BA, Guiltinan MJ. Isolation of ESTs from cacao (Theobroma cacao L.) leaves treated with inducers of the defense response. Plant Cell Rep. 2004;23(6):404-13.

55. Altschul SF, Gish W, Miller W, Myers EW, Lipman DJ. Basic local alignment search tool. J Mol Biol. 1990;215(3):403-10.

56. Kumar S, Tamura K, Nei M. MEGA3: Integrated software for molecular evolutionary genetics analysis and sequence alignment. Brief Bioinform. 2004:5(2):150-63.

57. Lazo GR, Stein PA, Ludwig RA. A DNA transformation-competent Arabidopsis genomic library in Agrobacterium. Biotechnology (N Y). 1991;9(10):963-7.

58. Lin JJ. Optimization of the transformation efficiency of Agrobacterium tumefaciens cells using electroporation. Plant Sci. 1994;101(1):11-5.

59. Clough SJ, Bent AF. Floral dip: a simplified method for Agrobacterium-mediated transformation of Arabidopsis thaliana. Plant J. 1998;16(6):735-43

60. Ahn JH. Semiquantitative Analysis of Arabidopsis RNA by Reverse Transcription Followed by Noncompetitive PCR. Cold Spring Harbor Protocols 2009, 2009. pdb.prot5296, doi:10.1101/pdb.prot5296.

\section{Submit your next manuscript to BioMed Central and take full advantage of:}

- Convenient online submission

- Thorough peer review

- No space constraints or color figure charges

- Immediate publication on acceptance

- Inclusion in PubMed, CAS, Scopus and Google Scholar

- Research which is freely available for redistribution 